\title{
Isolated adrenocorticotropin deficiency and flexion contractures syndrome
}

\author{
Vassiliki Syriou, Anestis Moisidis, Nikolaos Tamouridis, Krystallenia I. Alexandraki, \\ Margarita Anapliotou
}

Department of Pathophysiology, Division of Endocrinology, Athens University Medical School, Laiko Hospital, Athens, Greece

\begin{abstract}
We present a 73-year-old man with isolated adrenocorticotropic hormone deficiency and "flexion contractures" syndrome along with a review of the relevant literature. The patient initially presented anorexia, vomiting, arthralgias, malaise, and weight loss, which progressively deteriorated during the subsequent 6 months. He was admitted to the hospital with fever, confusion, severe cachexia, sinus tachycardia, low blood pressure, hyponatremia, and inability to stand or walk due to severe flexion contractures of the lower extremities (from hips to knees). The flexion contractures were not resolved by physiotherapy or diazepam administration. Due to his life-threatening condition the patient was empirically submitted to glucocorticoid replacement therapy and a remarkable relief from all the above symptoms was observed. A subsequent thorough endocrine investigation suggested the diagnosis of isolated ACTH deficiency (IAD) of unknown pathogenetic mechanism. Hence, in patients with "flexion contractures" syndrome, the pituitary adrenal axis should be evaluated.
\end{abstract}

Key-words: Cachexia, Flexion contractures, Hypoglycemia, Hyponatremia, Isolated ACTH Deficiency

\section{INTRODUCTION}

Adrenocorticotropic hormone (ACTH) deficiency is the most life-threatening feature of hypopituitarism. Isolated ACTH deficiency (IAD), although well defined, is very rare. ${ }^{1}$ Its clinical manifestations are similar to those of Addison's disease, i.e. weakness,

Address for correspondence:

Vassiliki Syriou, Department of Pathophysiology, Division of Endocrinology, Laiko Hospital, 75 Mikras Asias Str., GR11527 Athens, Greece, Tel: 2107462655, Fax: 2107462664, e-mail: vasyriou@med.uoa.gr

Received 10-01-08, Revised 06-07-08, Accepted 20-07-08 tiredness, nausea, vomiting, orthostatic hypotension, and most commonly anorexia and weight loss in the absence of skin hyperpigmentation. Hypoglycemia can occur, particularly in neonates with severe ACTH deficiency. Hyponatremia, although less common than in Addison's disease, might be the presenting feature, particularly in the elderly.

"Flexion contractures" syndrome is a rare clinical entity which consists of local or generalized, painful contractures of the flexor muscles of pelvic girdles, hips, and knees without any flexion of the extensor muscles. This syndrome usually reflects hypocortisolism. ${ }^{2,3}$ 
Stiff-man syndrome (also called Stiffman syndrome) is a rare neurologic syndrome characterized by spasticity of the axial muscles. ${ }^{4,5}$ The difference between these two syndromes is that in Stiff-man syndrome, agonist and antagonist muscles are affected equally and the patient becomes rigid in extension, whereas in "flexion contractures" syndrome the limbs are fixed in flexion. The etiology of either syndrome is obscure.

\section{PATIENT'S DESCRIPTION}

A 73-year old man, father of one son, was admitted to the hospital for evaluation. The onset of symptoms dated to two months previously and included anorexia, vomiting, arthralgias, tiredness, and weight loss (about $10 \mathrm{~kg}$ in the last 2 months). His previous medical history included hypertension which has been treated with $4 \mathrm{mg}$ perindopril daily.

Three weeks following his admission, the aforementioned symptoms persisted. The diagnosis of chronic atrophic gastritis was made and he was given therapy for Helicobacter pylori and sent home. One month later he was admitted to another hospital and after 45 days of investigation the diagnosis of a "low grade malignancy" (non-Hodgkin lymphoma) was made. The diagnosis was established by bone marrow aspiration biopsy since no obvious lymphadenopathy was present. He received two cycles of chemotherapy with a COP schema [cyclophosphamide (endoxan) $750 \mathrm{mg}$, vincristine sulfate (oncovin) $2 \mathrm{mg}$, and methylprednisolone (medrol) 48mg], each of 5 days duration. Even though he tolerated chemotherapy without any major side effects, twelve days after the second treatment course he was seen in the emergency room and admitted to the hospital. Physical examination then showed high fever, severe cachexia (weight loss from 85 to $47 \mathrm{Kg}$ in 5 months), sinus tachycardia, hypotension, confusion, and inability to stand up, his knees being in flexion, and no other neurologic findings. Laboratory investigation revealed a normocytic anemia [hematocrit (Ht): $28 \%$, mean corpuscular volume: 89 , with normal white blood cells and differential count], hyponatremia [serum sodium $\left(\mathrm{Na}^{+}\right): 115-122 \mathrm{mmol} / \mathrm{L}$ ), serum potassium: $4.1 \mathrm{mmol} / \mathrm{L}$, serum calcium: 2.375 $\mathrm{mmol} / \mathrm{L}$, creatine phosphate kinase (CPK): 964-2062 U/L (<180)], with the remaining biochemical pro- file and hepatic biochemistry within normal range. Diazepam and physiotherapy were ineffective. The above clinical and laboratory findings raised suspicion of chronic hypocortisolism and an endocrinological evaluation was requested. He reported no family or personal history of autoimmune diseases. There was no hyperpigmentation of the skin nor symptoms and/or signs of hypogonadism.

Thyroid function was normal [3,5,3'-triiodothyronine (T3): 1.29 (1.08-2.93 nmol/L), thyroxine (T4): $79.79(57.92-140.28 \mathrm{nmol} / \mathrm{L})$, thyroid stimulating hormone (TSH): 2.20 (0.4-4 mU/L); anti-thyroid peroxidase antibody (anti-TPO) and anti-thyroglobulin antibody (anti-TG) antibodies were negative; basal levels of ACTH were low: 0.44 (2.20-11.44 pmol/L)]. Cortisol (F) levels after $0.25 \mathrm{mg}$ tetracosactide depot given intramuscularly (Synacthen test) were normal; basal value: 402.76 (137.9-689.6 nmol/L), 2 hours: $1246.90 \mathrm{nmol} / \mathrm{L}$ [normal values $=$ double of baseline or $>827.59 \mathrm{nmol} / \mathrm{L}$ )], and 4 hours: 1710.58 (normal values $=\mathrm{x}^{2}$ or $\left.>827.59 \mathrm{nmol} / \mathrm{L}\right)($ Table 1$)$. The rest of the pituitary reserve was normal. Investigation for autoimmune diseases, including assessment of anti-skeletal muscle antibody (ASMA), anti-neutrophilic cytoplasmic antibodies (ANCA), antinuclear antibodies (ANA), anti-extractable nuclear antigen antibodies (anti-ENA), antimitochodrial antibody (AMA), antiparietal cell antibody (APCA), and antiglutamic acid decarboxylase (anti-GAD) antibodies, was negative.

Magnetic resonance imaging (MRI) of the pituitary-hypothalamic region was normal. Computerized tomography scans of chest and abdomen did not reveal pathologic findings except for diaphragmatic hernia. Electromyography (EMG) was silent. During the next three weeks the patient's condition progressively de-

Table 1. Synachten test (depot IM). Initial test carried out when clinical and laboratory findings raised suspicion of chronic hypocortisolism.

\begin{tabular}{lccc}
\hline & \multicolumn{3}{c}{ Synachten Test } \\
\cline { 2 - 4 } Time & $\mathbf{0}$ & 2 hours & 4 hours \\
\hline Cortisol $(\mathrm{nmol} / \mathrm{L})$ & 402.76 & 1246.90 & 1710.58 \\
ACTH $(\mathrm{pmol} / \mathrm{L})$ & 0.44 & & \\
\hline ACTH & & & \\
\hline
\end{tabular}

ACTH: adrenocorticotropic hormone, IM: intramuscular injection. 
teriorated. His body weight reached $42 \mathrm{Kg}$ and he lay constantly on the bed with his knees to the abdomen and heels to the buttocks (as in an embryo position). Hyponatremia was persistent $\left(\mathrm{Na}^{+}: 102-110 \mathrm{mmol} / \mathrm{L}\right)$. He experienced three symptomatic hypoglycemic episodes (glucose (GLU): $<2.22 \mathrm{mmol} / \mathrm{L}$ ), which subsided with glucose administration.

Due to his unexplained critical illness, hydrocortisone replacement therapy was decided upon, despite the normal response to the performed Synacthen test. A striking improvement of the clinical symptoms was observed. Initially, an improvement of consciousness level was noted, followed by normalization of hyponatremia and of blood pressure. A gradual remarkable improvement of the muscles spasticity in flexion was also noted. Finally, his appetite was restored, resulting in gradually regaining of his weight. Muscle biopsy was not carried out because of the complete remission of the contractures.

Two months later he was able to walk, he weighed $72 \mathrm{Kg}$, and his blood pressure was 130/70 $\mathrm{mmHg}$, while he had recovered a sense of well-being on substitution therapy with glucocorticoids (30 mg of hydrocortisone daily). His laboratory abnormalities were also reversed [Ht: $42 \%, \mathrm{Na}^{+}: 141 \mathrm{mmol} / \mathrm{L}, \mathrm{GLU}$ : $5.67 \mathrm{mmol} / \mathrm{L}$, CPK: $154 \mathrm{U} / \mathrm{L}(<180)]$. A dynamic pituitary test was performed after a $48 \mathrm{hr}$ interruption of hydrocortisone. The basal ACTH and cortisol values, as well as the cortisol response to Synacthen [intravenous injection (IV), $1 \mu \mathrm{g}$ ] and to the combined corticotropin-releasing hormone (CRH) + 1-deamino-8-D-arginine vasopressin (DDAVP) (100 $+10 \mu \mathrm{g}$ IV, respectively), confirmed an IAD (Table 2, 3, 4). Gonadotropin-releasing hormone (GnRH) and thyrotropin-releasing hormone $(\mathrm{TRH})$ stimulation tests were normal.

The patient has been followed up for 10 years and feeling well ever since with a daily administration of $20 \mathrm{mg}$ hydrocortisone and anti-hypertensive medication, maintaining a stable weight $(80 \mathrm{Kg})$ and with no relapse of his non-Hodgkin lymphoma.

\section{DISCUSSION}

Chronic adrenocortical insufficiency due to IAD is a rare clinical entity, first described by Steinberg
Table 2. Basal values prior to the second Synacthen test (two months after the initiation of hydrocortisone replacement therapy and 48 hours after hydrocortisone withdrawal).

\begin{tabular}{lcc}
\hline & Basal values & Normal values \\
\hline ACTH $(\mathrm{pmol} / \mathrm{L})$ & 3.7 & $2.2-11.44$ \\
Cortisol $(\mathrm{nmol} / \mathrm{L})$ & 2.76 & $137.95-689.95$ \\
TSH $(\mathrm{mU} / \mathrm{L})$ & 3.2 & $0.4-4$ \\
T4 $(\mathrm{nmol} / \mathrm{L})$ & 91.38 & $57.92-140.28$ \\
T3 $(\mathrm{nmol} / \mathrm{L})$ & 1.25 & $1.08-2.93$ \\
FSH $(\mathrm{IU} / \mathrm{L})$ & 5.7 & $<5$ \\
LH $(\mathrm{IU} / \mathrm{L})$ & 18.4 & $1-10$ \\
Testosterone $(\mathrm{nmol} / \mathrm{L})$ & 21.15 & $10.41-34.7$ \\
PRL $(\mu \mathrm{g} / \mathrm{L})$ & 0.2 & $<0.36$ \\
GH $(\mu \mathrm{g} / \mathrm{L})$ & 0.8 & $0-10$ \\
IGF-1 $(\mathrm{nmol} / \mathrm{L})$ & 17.26 & $9.15-40.53$ \\
\hline ACT
\end{tabular}

ACTH: adrenocorticotropic hormone, TSH: thyroid stimulating hormone, T4: thyroxine, T3: 3,5,3'-triiodothyronine, FSH: follicle stimulating hormone, LH: luteinizing hormone, PRL: prolactin, GH: growth hormone, IGF-1: insulin-like growth factor 1.

Table 3. Results of combined ACTH (adrenocorticotropic hormone), TRH (thyrotropin-releasing hormone), GnRH (gonadotropin-releasing hormone) test.

\begin{tabular}{cccccc}
\hline $\begin{array}{c}\text { Time } \\
(\mathbf{m i n})\end{array}$ & $\begin{array}{c}\text { Cortisol } \\
(\mathbf{n m o l} / \mathbf{L})\end{array}$ & $\begin{array}{c}\text { TSH } \\
(\mathbf{m U} / \mathbf{L})\end{array}$ & $\begin{array}{c}\text { PRL } \\
(\boldsymbol{\mu g} / \mathbf{L})\end{array}$ & $\begin{array}{c}\text { FSH } \\
(\mathbf{I U} / \mathbf{L})\end{array}$ & $\begin{array}{c}\mathbf{L H} \\
(\mathbf{I U} / \mathbf{L})\end{array}$ \\
\hline 0 & 2.76 & 3.2 & 0.2 & 5.7 & 18.4 \\
30 & 13.80 & 16.9 & 0.9 & 15.6 & 25.0 \\
60 & 8.28 & 14.9 & 0.7 & 12.2 & 23.1 \\
\hline
\end{tabular}

TSH: thyroid stimulating hormone, PRL: prolactin, FSH: follicle stimulating hormone, LH: luteinizing hormone.

Table 4. Results of CRH (corticotropin-releasing hormone) and DDAVP (1-deamino-8-D-arginine vasopressin) test.

\begin{tabular}{ccc}
\hline Time $(\mathbf{m i n})$ & ACTH $(\mathbf{p m o l} / \mathbf{L})$ & Cortisol $(\mathbf{n m o l} / \mathbf{L})$ \\
\hline-15 & 0.62 & $<27.59$ \\
0 & 0.27 & $<27.59$ \\
10 & 0.62 & $<27.59$ \\
15 & 0.40 & $<27.59$ \\
30 & 0.70 & $<27.59$ \\
45 & 0.59 & $<27.59$ \\
60 & 0.51 & $<27.59$ \\
\hline
\end{tabular}

ACTH: adrenocorticotropic hormone.

et al in $1954 .{ }^{6}$ About two hundred cases have thus far been described in the literature. The main causes of 
IAD are the following: 1) an autoimmune process (lymphocytic hypophysitis or autoantibodies against a corticotroph antigen); 2) congenital (observed in neonatal age) and caused by genetic defect; 3) incomplete infarction of the pituitary after delivery; 4) hypothalamic lesion due to birth trauma or head injury. ${ }^{7-11}$

Hyponatremia is rare in central adrenocortical insufficiency, since sodium balance is mainly regulated by the renin-angiotensin system. However, it is well known that longstanding chronic adrenal insufficiency without hydrocortisone replacement induces impaired mineralocorticoids secretion.

IAD has been associated with various autoimmune disorders, such as Graves' disease, ${ }^{12}$ Crohn's disease, ${ }^{13}$ Hashimoto's thyroiditis, ${ }^{14}$ myasthenia gravis, ${ }^{15}$ type 1 diabetes mellitus, ${ }^{16}$ and autoimmune adrenalitis. ${ }^{17}$

Flexion contractures syndrome is also considered a rare syndrome and in most reported cases is associated with Addison's disease or hypopituitarism and rarely with IAD..$^{3,18-20}$ It has also been reported as a paraneoplastic manifestation, ${ }^{21}$ which is not usually found in a low malignancy lymphoma like the one of the present case. The syndrome is characterized by: 1) progressive painful flexion contractures of the pelvic girdles, hips and knees without any problem in the extensor muscles, 2) variable EMG, 3) normal conduction velocity, no sensory abnormalities, and no findings of myopathy or myotonic discharges. ${ }^{2,3,18}$ The mechanism of the association with glucocorticoid deficiency is elusive, especially considering that this syndrome is rarely part of the manifestations of hypocortisolism.

Stiff-man syndrome is a disorder of the central nervous system characterized by rigidity of the body musculature and in which agonist and antagonist muscles are affected. The patient becomes rigid in extension and the EMG shows continuous motor unit activity with positive response to diazepam. Usually the muscle stiffness is symmetrical and episodic tetanic spasms arise via diverse stimulations (i.e. stress, fear). High titers of antibodies against glutamic acid decarboxylase are detected in approximately $60 \%$ of patients. The respiratory muscles may also be affected. ${ }^{4,5,18}$
The syndrome may coexist with autoimmune diseases, mainly insulin-dependent diabetes mellitus, Addison's disease, Graves' disease, Hashimoto's thyroiditis, pernicious anemia, and hypopituitarism, or be associated with polyglandular deficiency, implying an autoimmune etiology. ${ }^{4,5,22}$

To the best of our knowledge, our patient represents the fourth case ${ }^{18-20}$ of IAD associated with flexion contractures. Two cases of IAD have been reported in which IAD was associated with 'frozen shoulders', which is considered a focal flexion contractures syndrome. ${ }^{23,24}$ The diagnosis of IAD in our patient was based on the fact that baseline values and stimulatory test of the anterior pituitary function revealed an isolated insufficiency of the corticotroph cells. The mechanism involved is unknown, although it should be mentioned that an autoimmune basis cannot be excluded, since antipituitary antibodies against corticotroph cells antigens were not assessed. ${ }^{7}$ The co-existing atrophic gastritis, on the other hand, might be due to Helicobacter pylori gastritis or to autoimmunity. However, APCA antibodies were undetectable. Lymphocytic hypophysitis cannot be ruled out, though it seems unlikely because of negative history of autoimmune disorders and normal pituitary MRI.

The first Synacthen test, carried out in another hospital, was normal, although the patient presented obvious symptoms and signs of hypocortisolism. Despite this discordance, hydrocortisone replacement therapy was administered based on the patient's critical condition, with impressive reversion of symptoms. One may hypothesize that the initial test of adrenal reserve was carried out early in the course of the disease and the adrenal gland responded normally to the high dose synachten test $(250 \mu \mathrm{g})$ given IM, whereas the second was carried out using the $1 \mu \mathrm{g}$ dose synachten test. As far as the fixed patient position is concerned, differential diagnosis should always include flexion contractures syndrome and Stiff-man syndrome.

In conclusion, the flexed position of the patient, the absence of anti-GAD antibodies, the silent ${ }^{2} \mathrm{EMG}$, and the negative response to diazepam favor the diagnosis of flexion contractures syndrome.

It should finally be stressed that in a patient with 
this type of musculoskeletal abnormality, the pituitary-adrenal axis should be evaluated.

\section{REFERENCES}

1. de Luis DA, Aller R, Romero E, 1998 Isolated ACTH deficiency. Horm Res 49: 247-249.

2. Ebinger G, Six R, Bruyland M, Somers G, 1986 Flexion contractures: A forgotten symptom in Addison's disease and hypopituitarism. (letter). Lancet 11: 858.

3. Nishikawa T, 2003 Flexion contractures possibly reflect the existence of hypocortisolism (editorial). Intern Med 42: 629-631.

4. Solimena M, De Camilli P, 1991 Autoimmunity to glutamic acid decarboxylase (GAD) in Stiff-Man syndrome and insulin-dependent diabetes mellitus. Trends Neurosci 14: 452-457.

5. Levy ML, Dalakas CM, Floeter MK, 1999 The Stiff-Person Syndrome: An Autoimmune Disorder Affecting Neurotransmission of $\gamma$-Aminobutyric Acid. (NIH conference). An Int Med 131: 522-530.

6. Steinberg A, Shechter FR, Segal HI, 1954 True pituitary Addison's disease - A pituitary unitropic deficiency (fifteen-year follow-up). J Clin Endocrinol 14: 519-1529.

7. Sauter PN, Toni R, McLaughlin DC, Dyess ME, Kritzman J, Lechan MR, 1990 Isolated Adrenocorticotropin Deficiency Associated with an Autoantibody to a Corticotroph Antigen that is not Adrenocorticotropin or other Proopiomelanocortin-Derived Peptides. J Clin Endocrinol Metab 70: 1391-1397.

8. Richtsmeier AJ, Henry RA, Bloodworth JM Jr, Ehrlich EN, 1980 Lymphoid hypophysitis with selective adrenocorticotropin hormone deficiency. Arch Intern Med 40: 1243-1245.

9. Escobar-Morreale H, Serrano-Gotarredona J,Varela C, 1994 Isolated adrenocortical hormone deficiency due to probable lymphosytic hypophysitis in a man. J Endocrinol Invest 17: 127-131.

10. Jensen MD, Handwerger BS, Scheithauer BW, Carpenter PC, Mirakian R, Banks PM, 1986 Lymphocytic hypophysitis with isolated corticotropin deficiency. Ann Intern Med 105: 200-203.

11. Karavitaki N, Wass J, Henderson Slater JD, Wade D, 2006 A case of post-traumatic isolated deficiency with spontaneous recovery 9 months after the event. J Neurol
Neurosurg Psychiatry 77: 276-277.

12. Miyauchi S, Yamashita Y, Matsuura B, Onji M, 2004 Isolated ACTH deficiency with Graves' disease: a case report. Endocr J 51: 115-119.

13. Kalambokis G, Vassiliou V,Vergos T, Christou L, Tsatsoulis A, Tsianos EV, 2004 Isolated ACTH deficiency associated with Crohn's disease. J Endorinol Invest 27: 961-964.

14. Gürlek A, Nar A, Gedik O, 2001 Isolated adrenocorticotropic hormone deficiency, thyroid autoimmunity, and transient hyperprolactinemia. Endocr Pract 7: 102-105.

15. Corcuff JB, Lafranque P, Henry P, Roger P, 1997 Isolated corticotroph insufficiency associated to myasthenia gravis. J Endocrinol Invest 20: 669-671.

16. Yoshida T, Yoshioka K, Umekawa T, Kondo M, 1995 Severe hypoglycemia and type I diabetes with isolated ACTH deficiency. Sakane N. Diabetes Care 18: 16211622.

17. Silva OL, 1991 Isolated aldosterone deficiency and autoimmune adrenalitis. Am J Med 90: 124.

18. Odagaki T, Noguchi Y, Fukui T, 2003 Flexion contractures of the legs as the initial manifestation of adrenocortical insufficiency. Intern Med 42: 710-713.

19. Nakamagoe K, Ohkoshi N, Ishii A, Oguni E, Mizusawa H, 1994 Syndrome of contracture facio-brachio-abdomino-crurale en flexion in a case of isolated ACTH deficiency-biopsy findings of muscle and nerve. Rinsho Shinkeigaku 34: 250-254.

20. Yabuki S, Shiomi F, 1984 Syndrome of "contracture facio-brachio-abdomino-crurale en flexion" in a case of isolated ACTH deficiency. Rinsho Shinkeigaku 24: 729-735.

21. Eekhoff EMW, van der Lubbe PA, Breedveld FC, 1998 Flexion contractures associated with a malignant neoplasm: 'A Paraneoplastic Syndrome?' Clin Rheumatol 17:157-159.

22. Chroni E, Papadimitriou A, Avramidis T, Terentiou AE, Tzioras C, Divari R, 2000 Stiff-person-like syndrome in a patient with multiple pituitary hormone deficiencies. Acta Neurol Scand 102: 403-405.

23. Romney SJ, Chik LC, 2001 Frozen Shoulders: An Endocrine Disease? A Case Report of Isolated ACTH Deficiency. The Endocrinologist 11: 429-431.

24. Choy EH, Corkill MM, Gibson T, Hicks BH, 1991 Isolated ACTH deficiency presenting with bilateral frozen shoulder. Br J Rheumatol 30: 226- 227. 